\title{
COCINAR LAS PALABRAS QUE QUEDAN. UN ANÁLISIS DE PRÁCTICAS LINGÜÍSTICAS Y CULINARIAS DEL PUEBLO BORÁN
}

\section{COOKING THE REMAINIG WORDS. AN ANALYSIS OF LINGUISTIC AND CULINARY PRACTICES OF THE BORÁN PEOPLE}

\author{
Nicole Cisneros Vargas \\ Universidad de Costa Rica \\ nicole.cisneros@ucr.ac.cr
}

Recibido: 28 de octubre de 2021 / Aprobado: 31 de octubre de 2021 / Publicado: 11 de noviembre de 2021

Resumen: Las tradiciones y la lengua de un pueblo generalmente reflejan su concepción de mundo y muestran las condiciones en las que se ha desarrollado; con el fin de identificar estos elementos en la comunidad indígena de Brorán, localizada en la provincia de Puntarenas, Costa Rica, se analizarán los ingredientes más frecuentes, las técnicas culinarias empleadas y la presentación final de las recetas documentadas en el Diccionario-recetario pictográfico de la alimentación tradicional en Brörán̈ qu'ercuó (el idioma de Térraba) para categorizar el proceso culinario de este pueblo indígena a partir de las nociones de Claude Lévi-Strauss.

Palabras clave: Conocimientos tradicionales, costumbres alimenticias, cultura tradicional, etnolingüística, preparación de alimentos, población indígena

\begin{abstract}
Traditions and language of a people generally reflect its conception of the world and show the conditions in which it has developed; in order to identify these elements in the indigenous community of Brorán, located in the province of Puntarenas, Costa Rica, this article analyze the most frequent ingredients, the culinary techniques and the final presentation of the recipes documented in Diccionario-recetario pictográfico de la alimentación tradicional en Brörán̈ qu'ercuó (the Terraba language) to categorize the culinary process of this indigenous people based on the notions of Claude Lévi-Strauss.
\end{abstract}


Keywords: Ethnolinguistics, food customs, food preparation, indigenous peoples, traditional cultures, traditional knowledge ,

\section{LOS BRORÁN Y LA PÉRDIDA DE SU LENGUA}

El pueblo indígena de Brorán, también llamado Térraba, es uno de los ocho pueblos indígenas de Costa Rica; es una comunidad integrada por 200 personas que habitan en el pueblo San Francisco de Térraba, ubicado en el cantón de Buenos Aires, de la provincia de Puntarenas, cuya lengua se encuentra en proceso de muerte, pues no existe una transmisión intergeneracional de la lengua desde hace varias décadas. Según la información del Censo del 2011, el $10 \%$ de los habitantes de Térraba habla la lengua indígena; no obstante, Sánchez (2013) advierte que en la actualidad no se encuentran hablantes fluidos de la lengua ancestral, solo quedan vestigios de lo que en alguna ocasión escucharon hablar a sus antecesores.

Ante este panorama, la lengua de Brorán se podría considerar extinta; sin embargo, muchos miembros de la comunidad, "aunque no puedan emplearla para entablar una conversación o producir textos, parecen conocer 'remanentes' y son plenamente conscientes de que estos forman parte de su lengua ancestral, al punto de que usan palabras y expresiones en el idioma (forma en la que usualmente se refieren a la lengua de Brorán) deliberadamente" (Sánchez, 2013 p. 34); asimismo, de forma constante reafirman su deseo de aprender la lengua ancestral, por lo que participan de iniciativas que buscan recuperar sus tradiciones y su idioma.

Es una comunidad, por tanto, deseosa de apoyar proyectos para la revitalización lingüística, esta última entendida como volver a cierto nivel de uso de la lengua y no como la restauración de su vitalidad plena (Hinton, 2011), para lo cual se recomienda iniciar con temas específicos, preferiblemente asociados a prácticas culturales de la propia comunidad, pues con la pérdida de una lengua los hablantes experimentan también "una pérdida de su identidad étnica y cultural original" (Unesco, p. 2). De ahí que recuperar vocabulario asociado a prácticas culturales implica una mayor identificación e involucramiento.

Ese fue el caso con la comunidad de Brorán, la cual participó en manera activa de la elaboración del Diccionario-recetario pictográfico de la alimentación tradicional en Brörán̈ qu'ercuó (el idioma de Térraba), que buscaba 
recopilar recetas culinarias tradicionales y traducirlas a su idioma, con fines educativos, pues se espera que empleen el vocabulario relacionado con los ingredientes, instrumentos, procesos de cocimiento, a la vez que adquieren la gramática de oraciones cortas e instruccionales, pues de esa manera podrán recurrir a su lengua cuando se encuentren en un contexto culinario.

Este Diccionario-recetario es una documentación desarrollada en el marco del proyecto "Diversidad lingüística de Costa Rica", adscrito a la Escuela de Filología, Lingüística y Literatura y a la Vicerrectoría de Acción Social de la Universidad de Costa Rica, por el lingüista Carlos Sánchez Avendaño con miembros de la comunidad de Brorán y esta investigadora, para elaborar un diccionario sobre las tradiciones culinarias de ese pueblo indígena.

En esa ocasión, participaron en la preparación de recetas Rosa Cabrera Delgado, Marilyn Cabrera Delgado, Mery Porras Cabrera, Patrocinio Cabrera Zúñiga, Pascual Cabrera Ortiz, Antonio Nájera Rivera, Emilce Rivera Guillén, Jorge Navas Rojas, Asdrúbal Rivera Villanueva y Paulino Nájera Rivera, todos del pueblo de Brorán. También contribuyeron Inés Villagra Sánchez y Florencio Gamarra Rodríguez en la traducción, pues la lengua de Brorán no cuenta ya con hablantes nativos, por lo que se recurre a hablantes de la variedad panameña que viven en el territorio Térraba para revisar el léxico que con antelación registró Constenla (2007) y completar el vocabulario faltante relacionado con las recetas que se recopilaron.

\section{EL DISCURSO CULINARIO}

Claude Lévi-Strauss (2013) plantea la existencia de un triángulo culinario que incluye las nociones de "crudo", "cocido" y "podrido" como los estados de las materias primas en el proceso gastronómico, dentro de los que enmarca a la parrilla, lo asado, ahumado, hervido, cocido y fermentado; para este autor, lo cocido refiere a una transformación de lo crudo desde un punto de vista cultural, mientras que lo podrido es un proceso natural; por tanto, establece las dicotomías elaborado/no elaborado y cultural/natural, cuyo significado dependerá de cada sociedad y de los modos de cocción (o de transformación, según otros autores) que se utilicen, pues si una comida se asa o se hierve no implicará solo un acabado distinto, sino una significado cultural importante. 
Por otra parte, a partir de un recetario escrito en 1957, Viudas (1982) explica que el discurso culinario en español cuenta con un código lingüístico que se caracteriza por "indicar los elementos que entran en la composición y elaboración de un plato de cocina y la manera en que se prepara” (p. 220); así, según este autor, cada receta contiene textos de poca extensión constituidos por dos partes: el indicador y el enunciado. El indicador es el título de la receta, pues este aclara "el contenido de cada receta con el menor número de palabras posible” (p. 221), que puede constar de una estructura sintáctica simple -es decir, un solo elemento, predominantemente nominal-o compleja -si lo acompañan otros elementos sintácticos.

El enunciado, por su parte, es el procedimiento que un autor narra para un futuro usuario mediante la segunda persona singular, en los modos indicativo e imperativo, y siempre con una finalidad práctica. En el enunciado, se indican los elementos básicos o las materias primas que "se mezclan en unas determinadas proporciones, se condimentan y preparan y se sirven a los comensales guardando unas reglas" (p. 227).

Sobre las materias primas, Eberenz (2016) también analiza textos de la literatura culinaria española y aclara que se pueden clasificar en tipologías dependiendo de la disciplina desde donde se analiza el discurso o la práctica culinaria; no obstante, la dicotomía de alimentos simples/alimentos preparados se presenta en la mayoría de los enfoques. La primera se relaciona con la noción de crudo propuesta por Lévi-Strauss, mientras la segunda implica una transformación a partir de su cocimiento.

Este autor afirma que "todo plato es el resultado de un proceso de elaboración” (p. 83), por lo que da especial énfasis a los verbos que se emplean en las preparaciones culinarias desde la Edad Media hasta las primeras décadas del siglo XVII, cuya clasificación se complementa con la propuesta por Lehrer (1972), quien basada en la teoría de Lévi-Strauss plantea una segmentación de los procesos de cocción bajo las dicotomías [ \pm agua] y [ \pm grasa] si se refiere al uso de aceites o bases acuosas. Esta autora considera también [ \pm calor directo], pues el calor es un elemento fundamental en el proceso de transformación culinaria.

De igual forma, Eberenz (2016) destaca la presencia de procedimientos de transformación sin el uso del fuego, como batir, cortar, escurrir, exprimir, majar, rallar, entre otros; además de las técnicas de elaboración que permiten 
conservar los alimentos, entre ellas fermentar, ahumar, salar, secar, confitar (esta última más cerca de la clasificación “podrido" de Lévi-Strauss). A esto, Lehrer (1972) le denomina [Propósito especial previsto por el proceso de cocción], que se refiere a procesos culinarios para preservar lo cocinado o suavizar la materia prima.

Además, las técnicas culinarias también están estrechamente relacionadas con el tipo de recipiente en el que se lleva a cabo; por ejemplo, las cazuelas para hacer guisos, las ollas para cocinar caldos; para lo cual Lehrer (1972) considera la categoría [utensilio especial] cuando se requiere de un sartén para freír -cuya función antiadherente evita el uso de grasa-, o de carbones calientes para asar a las brasas. Por último, Lehrer (1972) añade [uso especial de ingredientes o comida preparada], como un aditamento relacionado con el sabor.

\section{LOS BRORÁN Y SUS TRADICIONES CULINARIAS}

Mientras un grupo cocina en un fogón y nos enseña sus recetas tradicionales en español, dos adultos mayores -hombres líderes de la comunidad, quienes ya fallecieron- permanecen sentados en sus hamacas conversando sobre la comida que identifican como propia de su pueblo e intentan recordar cómo le llamaban sus antepasados. Prueban algunos platillos y lamentan que sus tradiciones y su idioma se estén perdiendo.

Si bien cuando se documentan prácticas culturales para fines de revitalización lingüística lo ideal es recopilar la información en la lengua originaria, en algunos casos esta se encuentra en un estado tan avanzado de desplazamiento que no puede establecerse una comunicación, como es el caso de la lengua de Brorán. A pesar de ello, para miembros de esta comunidad reunirse y rememorar la herencia gastronómica que dejaron sus antecesores, con el objetivo de plasmarlo en un escrito, es volver a sus raíces, pues incluye explicar por qué se debe usar hojas de bijagua en los tamales de arroz, mostrar cómo se aprovechan las partes de un cerdo, escuchar cómo cambia el sonido de las semillas al cocerse, entre otros.

De ahí surgió la inquietud de analizar las recetas incluidas en el Diccionario-recetario pictográfico de la alimentación tradicional en Brörán̈ qu'ercuó (el idioma de Térraba) a partir de la clasificación del triángulo culinario de Claude Lévi-Strauss, para categorizar el procedimiento gastronómico 
tradicional y, con base en ello, identificar los elementos identitarios en la preparación de alimentos, tomando en consideración los ingredientes, las técnicas de cocción, las acciones realizadas y los nombres de las recetas dentro del Diccionario-recetario.

La procedencia de los ingredientes es importante para identificar lo mínimo requerido para preparar un alimento; así, la clasificación de simple o preparado advierte si la materia prima implica un proceso de transformación previo o no; si bien, Lévi-Strauss propone "crudo" y no "simple", se decidió optar por la propuesta de Eberenz (2016) debido a que un alimento puede haber sufrido una transformación previa y mantenerse crudo, por lo que se consideró más preciso hablar de simples cuando se toma el ingrediente tal cual es provisto por la naturaleza.

Por tanto, en este caso se han clasificado los ingredientes de la siguiente manera: alimento simple de origen vegetal, alimento de origen animal, alimento de origen mineral y alimento preparado, cuyos resultados arrojan que la mayoría de ingredientes presentes en el Diccionario-recetario son simples y de origen vegetal, ya que solo unos pocos son de origen animal o mineral y tan solo una minoría (apenas cuatro) son preparados, de los cuales uno (la manteca) requiere un proceso de cocción. En términos de ingredientes, entonces, casi en su totalidad se ubican en la categoría "crudo" de Lévi-Strauss, según se puede apreciar en la Tabla 1. 


\section{Tabla 1}

Clasificación de ingredientes en las recetas recopiladas para el Diccionario-recetario pictográfico de la alimentación tradicional en Brörán“ qu'ercuó (el idioma de Térraba)

\begin{tabular}{|c|c|c|}
\hline Clasificación & Término en lengua de Brorán & Término equivalente en español \\
\hline $\begin{array}{l}\text { 1. Alimento simple } \\
\text { de origen vegetal }\end{array}$ & $\begin{array}{l}\text { bó } \\
\text { c'uofrurún } \\
\text { có } \\
\text { cuó } \\
\text { cuóta } \\
\text { cuohuó } \\
\text { ë’b } \\
\text { guënmó } \\
\text { shpágro } \\
\text { ibín“ } \\
\text { ibó } \\
\text { íc } \\
\text { québin“ } \\
\text { shtahuó } \\
\text { shúb } \\
\text { srórbo } \\
\text { shún“guo } \\
\text { yáco } \\
\text { zhóc } \\
\text { dió }\end{array}$ & $\begin{array}{l}\text { fruto } \\
\text { arroz } \\
\text { cacao } \\
\text { grano } \\
\text { cáscara } \\
\text { semilla } \\
\text { elote, maíz } \\
\text { naranja } \\
\text { limón } \\
\text { plátano } \\
\text { chile } \\
\text { yuca } \\
\text { banano } \\
\text { frijoles } \\
\text { pejibaye } \\
\text { caña de azúcar } \\
\text { achiote } \\
\text { culantro de coyote } \\
\text { pacaya } \\
\text { líquido / jugo }\end{array}$ \\
\hline $\begin{array}{l}\text { 2. Alimento de } \\
\text { origen animal }\end{array}$ & $\begin{array}{l}\text { ácuor } \\
\text { bö'mcuo } \\
\text { cógo } \\
\text { c’ríro } \\
\text { dobógro } \\
\text { óhua } \\
\text { nepcuógra } \\
\text { sën“ } \\
\text { së'n“na } \\
\text { zhán“cógro }\end{array}$ & $\begin{array}{l}\text { huevo } \\
\text { pescado } \\
\text { cabeza } \\
\text { gallina } \\
\text { hueso } \\
\text { animal } \\
\text { cerdo } \\
\text { carne } \\
\text { carne } \\
\text { intestinos }\end{array}$ \\
\hline $\begin{array}{l}\text { 3. Alimento de } \\
\text { origen mineral }\end{array}$ & $\begin{array}{l}\text { drún }{ }^{\circ} \\
\text { dí }\end{array}$ & $\begin{array}{l}\text { sal } \\
\text { agua }\end{array}$ \\
\hline $\begin{array}{l}\text { 4. Alimento } \\
\text { preparado }\end{array}$ & $\begin{array}{l}\text { prú } \\
\text { prúñ ‘sho } \\
\text { shó } \\
\text { qu'ióyo }\end{array}$ & $\begin{array}{l}\text { condimento } \\
\text { harina } \\
\text { masa } \\
\text { manteca }\end{array}$ \\
\hline
\end{tabular}

Fuente: Elaboración propia 
Cabe resaltar que los ingredientes más mencionados en las recetas son dí 'agua' y ếb 'maíz', con 19 apariciones cada uno, lo que da una idea de la importancia cultural de esos elementos y, por ende, el proceso culinario más usado en las recetas recopiladas, según se verá a continuación.

Además de analizar los ingredientes, es necesario identificar los procesos de transformación de esa materia prima, pues, en concreto, ese es el fin del proceso culinario; para su clasificación, se tomó como base lo propuesto por Eberenz (2016) y Lehrer (1972): “sin uso del fuego", "aplicación de calor" y "técnicas de conservación o almacenamiento"; asimismo, esta clasificación que se ha asociado a las nociones planteadas por Lévi-Strauss de "crudo", "asado", "cocido", "ahumado", "hervido" y "fermentado". Vale indicar que la mayoría de estos procesos de transformación corresponden a acciones para el "paso a paso" de las recetas, y, en algunos casos, su equivalente en español es casi igual a las nociones de Lévi-Strauss; de esa manera se puede identificar que las técnicas culinarias más comunes para preparar los alimentos en esta cultura indígena son procesos de transformación en los que no se aplica el fuego, según puede observarse en la Tabla 2. 
COCINAR LAS PALABRAS QUE QUEDAN. UN ANÁLISIS DE PRÁCTICAS LINGÜÍSTICAS Y CULINARIAS DEL PUEBLO BORÁN

Tabla 2

Verbos de transformación de la materia prima en las recetas recopiladas para el Diccionario-recetario

\begin{tabular}{|c|c|c|c|}
\hline Clasificación & $\begin{array}{l}\text { Clasificación según } \\
\text { Lévi-Strauss }\end{array}$ & $\begin{array}{l}\text { Término en lengua } \\
\text { de Brorán }\end{array}$ & $\begin{array}{l}\text { Término equivalente en } \\
\text { español }\end{array}$ \\
\hline $\begin{array}{l}\text { 1. Procedimiento de } \\
\text { transformación sin } \\
\text { uso del fuego }\end{array}$ & crudo & $\begin{array}{l}\text { zế } \\
\text { zhurúc } \\
\text { shóishru } \\
\text { froyế } \\
\text { iodế } \\
\text { irórhuë } \\
\text { c'uocá } \\
\text { coshcuế } \\
\text { dó } \\
\text { shcué } \\
\text { cŕóc } \\
\text { ŕashá } \\
\text { ropsaŕá } \\
\text { shgrế } \\
\text { shóishru } \\
\text { shopshí } \\
\text { shrín̈ } \\
\text { tiế }\end{array}$ & $\begin{array}{l}\text { cortar } \\
\text { amasar } \\
\text { amasar } \\
\text { ventear } \\
\text { agregar } \\
\text { mezclar } \\
\text { desgranar } \\
\text { lavar } \\
\text { quitar } \\
\text { pelar } \\
\text { moler } \\
\text { colar } \\
\text { revolver } \\
\text { majar } \\
\text { amasar } \\
\text { estirar } \\
\text { raspar } \\
\text { agregar }\end{array}$ \\
\hline 2. Aplicación de calor & $\begin{array}{l}\text { Asado } \\
\text { cocido } \\
\text { cocido } \\
\text { hervido } \\
\text { cocido } \\
\text { cocido }\end{array}$ & $\begin{array}{l}\text { súc } \\
\text { ríc } \\
\text { c'rírque } \\
\text { dugốn } \\
\text { yốcsea go } \\
\text { dŕó í }\end{array}$ & $\begin{array}{l}\text { asar } \\
\text { cocer } \\
\text { calentar } \\
\text { hervir } \\
\text { a las brasas } \\
\text { al sol }\end{array}$ \\
\hline $\begin{array}{l}\text { 3. Técnicas de } \\
\text { conservación o } \\
\text { almacenamiento de } \\
\text { alimentos }\end{array}$ & $\begin{array}{l}\text { fermentado } \\
\text { Ahumado } \\
\text { Ahumado } \\
\text { Ahumado } \\
\text { fermentado }\end{array}$ & $\begin{array}{l}\text { cuirque } \\
\text { idán } \\
\text { dión̈ } \\
\text { ñógo í } \\
\text { shpä̈ }\end{array}$ & $\begin{array}{l}\text { madurar } \\
\text { secar } \\
\text { ahumar } \\
\text { al humo } \\
\text { agriar }\end{array}$ \\
\hline
\end{tabular}

Fuente: Elaboración propia. 
Lo anterior resulta curioso, por cuanto también se analizaron los títulos de las recetas y ninguno de los procesos recopilados en este Diccionario-recetario se sirve crudo; es decir, aunque mayoritariamente en el proceso no se aplique el fuego, al final de la receta sí necesitará de este elemento, según consta en la Tabla 3. Por otra parte, la variedad de palabras para determinar las acciones no asociadas al fuego evidencia la importancia de estos procesos en la gastronomía del pueblo de Brorán, dentro de las que destaca moler como una de las acciones tradicionales que se están perdiendo.

Tabla 3

Recetas presentes en el Diccionario-recetario según Lévi-Strauss

\begin{tabular}{|c|c|c|}
\hline Clasificación & Nombre de la receta & Nombre equivalente en español \\
\hline Asado & $\begin{array}{l}\text { sốmcuo } \\
\text { bï̈zá } \\
\text { bómcuo súi c'róga iroi } \\
\text { íc súc í }\end{array}$ & $\begin{array}{l}\text { tortilla grande asada } \\
\text { banano verde asado } \\
\text { pescado asado en hoja } \\
\text { yuca asada }\end{array}$ \\
\hline Cocido & $\begin{array}{l}\text { igapcuó } \\
\text { suin̈gá }\end{array}$ & $\begin{array}{l}\text { tortilla } \\
\text { tortilla de plátano maduro }\end{array}$ \\
\hline Ahumado & $\begin{array}{l}\text { sến̈na shó dión̈ ñógo í } \\
\text { sến zhánógro iroi }\end{array}$ & $\begin{array}{l}\text { carne ahumada } \\
\text { chorizo }\end{array}$ \\
\hline Hervido & $\begin{array}{l}\text { có dió } \\
\text { íc ríc í } \\
\text { c'uofrurún igá } \\
\text { ếb igá } \\
\text { birín̈go óco } \\
\text { ëb jốnio } \\
\text { bï̈sŕó jönnio } \\
\text { ibin̈ quësón̈ ŕii } \\
\text { ếb cuó sê̈n̈ t'oc dió }\end{array}$ & $\begin{array}{l}\text { chocolate } \\
\text { yuca sancochada } \\
\text { tamal de arroz } \\
\text { tamal de maíz } \\
\text { tamal de banano } \\
\text { atol de maíz } \\
\text { atol de banano seco } \\
\text { banano verde sancochado } \\
\text { pozol }\end{array}$ \\
\hline Fermentado & $\begin{array}{l}\text { shúb ó } \\
\text { ëb ó } \\
\text { shpócten̈ }\end{array}$ & $\begin{array}{l}\text { chicha de pejibaye } \\
\text { chicha de maíz } \\
\text { atol agrio y fermentado }\end{array}$ \\
\hline
\end{tabular}

Fuente: Elaboración propia. 
En esta última tabla se demuestra la relevancia del agua en la alimentación de Brorán, pues es uno de los ingredientes más mencionados en las recetas, como se indicó con anterioridad; su presencia, por tanto, resulta protagonista en la mayoría de las preparaciones, sea para culminar con el proceso culinario (como es el caso de los tamales) o porque forma parte de la presentación final (como el pozol y las bebidas). En consecuencia, la mayoría de las recetas implicarán un proceso de hervor o en el caso de la chicha, de fermentación.

En su propuesta, Lévi-Strauss menciona la trascendencia del agua en las culturas ancestrales por los recipientes de porcela o madera que pasan de generación en generación; sin embargo, este no es el caso del pueblo de Brorán, pues aunque sin duda el elemento acuoso es imprescindible, en los datos recolectados no se percibe ese apego emocional y familiar con respecto a los recipientes, ya que el tipo de envases que utilizan es de origen vegetal, tal como hojas de bijagua y guacales, por ser elementos fáciles de desechar una vez acabada la comida.

En cuanto a lo ahumado, no tiene tanta presencia en este corpus, pues solo dos recetas recurren a esa técnica, aunque ambas con la carne de cerdo como ingrediente base, lo que muestra la importancia de este proceso para evitar su descomposición, ya que a diferencia de la materia prima de origen vegetal -que pueden tomar cuanto necesiten según el número de porciones-al cerdo deben prepararlo por completo y asegurar que siga siendo comestible hasta que terminen de consumirlo, lo cual podría conllevar varios días. Debido a que en este Diccionario-recetario la mayoría de las recetas son hechas a base de productos vegetales, el ahumado no resulta necesario, a excepción de las dos recetas mencionadas.

Por su parte, lo asado resulta con mayor protagonismo que lo ahumado, para lo cual los productos se envuelven en hojas y se colocan directamente en las brasas, puede que por la facilidad de su preparación a lo largo del río, ya que el río Grande de Térraba fue, durante mucho tiempo, un medio de movilización hacia pueblos vecinos, donde comercializaban, cuyo viaje tardaba hasta una semana.

Respecto a otras categorías, Lévi-Strauss en ese mismo artículo reflexiona incorporar el uso del aceite, para proceder a otros métodos como freír; sin embargo, ni el autor lo incluye en su triángulo ni en el corpus se 
evidencia el método, pues a pesar de que dentro de la materia se menciona la manteca, solo aparece en la receta del tamal de arroz para cocinar la carne de cerdo, pero no al grado de considerarse frito; de hecho, no se registra un verbo para dicha acción, la carne se pone en el aceite.

\section{A MODO DE CONCLUSIÓN}

Tal como muestran los resultados, los procedimientos culinarios en la tradición Brorán generalmente no implican un uso del fuego, pues a lo largo de la receta lo más común es hallar acciones como cortar, moler - tan importante en su cultura-, revolver, amasar, entre otros; sin embargo, en las recetas analizadas no se incluye ninguna que se sirva cruda, ya que todas concluyen con un proceso de cocción, en especial en agua, uno de los ingredientes más presentes en estas recetas, sea porque los ingredientes solo se hierven o porque también se presentan con consistencia líquida, como es el caso de las bebidas o el pozol.

Al respecto, se observa cómo las circunstancias geográficas determinan ciertos procesos culturales, como su alimentación. Por ejemplo, en cuanto a ingredientes, debido a que era común que la población atravesara el río para movilizarse a otras comunidades, era más sencillo obtener alimentos que provenían de la vegetación que esperar pacientemente la aparición de un animal para ser cazado. Si bien también cuentan con ingredientes de procedencia animal, en esta ocasión se documentaron las recetas con predominancia vegetal.

Por otra parte, sus técnicas de cocción también evidencian esa realidad, pues asar y hervir resultan más expeditos que ahumar, y a estas técnicas tenían que recurrir cuando viajaban por el río de Térraba, en búsqueda de otros ingredientes que no eran propios de la región, como la sal. También, los materiales para asar o hervir podían ser conseguidos con facilidad en los alrededores del río. Por ese motivo muchos de los recipientes usados (los cuales no fueron incluidos en este análisis) son también de origen vegetal, ya que no era práctico viajar con vasijas con las que tendrían que devolverse, debido al peso. Cuando salían de su tierra era en una balsa, río abajo, pero cuando regresaban a su casa lo hacían a pie, por lo que debían evitar pesos extra para transportar más mercancía hacia sus hogares. 


\section{REFERENCIAS BIBLIOGRÁFICAS}

Constenla, A. (2007). La lengua de Térraba: esbozo fonológico y gramatical, y pequeño diccionario. Editorial UCR. San José Costa Rica.

Eberenz, R. (2016). "De lo crudo a lo cocinado: sobre el léxico fundamental de la culinaria en la historia del español (siglos XIII a XVII). En Revista de Filología Española XCVI, Vol. 96, n. ${ }^{\circ}$ 1, pp. 81-112

Hinton L. "Revitalization of endangered languages". En The Cambridge Handbook of Endangerment Languages. Cambridge: Cambridge University Press. 2011.

Lehrer, A. (1972) "Cooking Vocabularies and the Culinary Triangle of Lévi-Strauss". En Anthropological Linguistics, Vol. 14, n. ${ }^{\circ}$ 5, pp. 155-171

Lévi-Strauss, C. 2013 "The Culinary Triangle." In Food and Culture: A Reader. ed. Counihan, Carole and Van Esterik, Penny. Routledge

Sánchez, C. (2013) "Lenguas en peligro en Costa Rica: vitalidad, documentación y descripción”. En Káñina, Rev. Artes y Letras. XXVII (1): 219-250

Sánchez, C. et al. (2016). Diccionario-recetario pictográfico de la alimentación tradicional en Brörán̈ qu'ercuó (el idioma de Térraba). Universidad de Costa Rica

Unesco. Vitalidad y peligro de desaparición de las lenguas. Documento adoptado por la Reunión Internacional de Expertos sobre el programa de la UNESCO "Salvaguardia de las Lenguas en Peligro". París, 2003.

Viudas, A. (1982). El lenguaje técnico de un recetario de cocina. Anuario de Estudios Filológicos, 5, 219-229 